\title{
Pandemia de covid-19: \\ o SUS mais necessário do que nunct
}

\author{
Aylene Bousquat \\ Marco Akerman \\ Áquilas Mendes \\ Marília Louvison \\ Paulo Frazão \\ Paulo Capel Narvai
}




\section{resumo}

A discussão sobre as diversas formas de organizar sistemas e serviços de saúde não se restringe mais aos especialistas e passou a ocupar um espaço significativo tanto na mídia comercial e nas redes sociais quanto nas conversas do cotidiano na vigência da pandemia de covid-19. No caso brasileiro, o SUS foi objeto de constantes ataques nos últimos anos. Observa-se uma sucessão de políticas de desmantelamento associadas a um quadro de brutal desfinanciamento. Após o início da pandemia esse quadro começou a apresentar mudanças e o SUS passou a ser valorizado positivamente, registrando-se depoimentos em sua defesa, vindos de bocas e lavras nas quais jamais estiveram presentes. Nesse sentido, este artigo aponta as principais fragilidades e fortalezas do SUS tanto no enfrentamento da pandemia de covid-19, quanto na sua caminhada na direção de um sistema universal de saúde mais efetivo.

Palavras-chave: sistemas universais de saúde; SUS; covid-19; financiamento.

\section{abstract}

The discussion on the various ways of organizing health systems and services is no longer restricted to specialists. It has come to occupy a significant space both in the commercial media and social networks and in everyday conversations during the covid-19 pandemic. In the Brazilian case, SUS has been the target of constant attacks in recent years. There is a succession of decommissioning policies associated with a scenario of brutal disinvestment. After the beginning of the pandemic, this situation began to show changes. SUS started to be positively valued, registering testimonies in its defense, coming from mouths it had never been present before. In this sense, this article points out the main weaknesses and strengths of SUS both in coping with the covid-19 pandemic and in its journey towards a more effective universal health system.

Keywords: universal health systems; SUS; Covid-19; financing. 


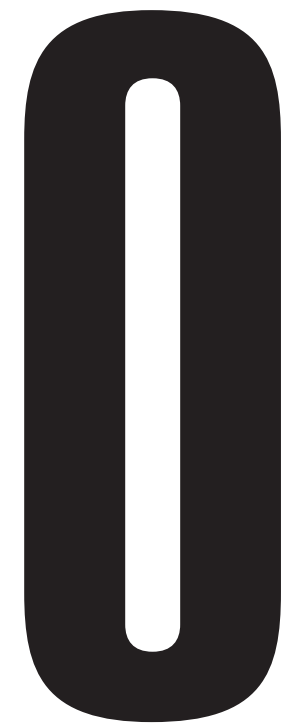

enfrentamento da pandemia de covid-19 cobra mais do que nunca políticas sociais efetivas e amplas, como tem ficado cada vez mais claro no debate mundial (Santos, 2020; "Covid19...", 2020). Dentre as políticas sociais, evidentemente a política de saúde se destaca e tem sido objeto de intensos debates. A discussão sobre as diversas formas de organizar sistemas e serviços de saúde não se restringe mais aos especialistas e passou a ocupar um espaço significativo tanto na mídia comercial e nas redes sociais quanto nas conversas do cotidiano. Chama a atenção uma importante mudança do enfoque da imprensa em relação aos sistemas de saúde, especialmente aos sistemas universais. Até bem recentemente, predominavam críticas e ataques aos sistemas com essa característica, como o Sistema Único de Saúde (SUS) e o National Health Service (NHS) britânico, quando o assunto era abordado. A mágica solução, quase sempre proposta para reverter a suposta ineficiência, seria a privatização. A expressão é uma espécie de panaceia que se aplica a qualquer mal, real ou fictício. A pandemia de covid-19 parece provocar a inversão dessa tendência. Surpreendentemente, as páginas dos cadernos de economia, tradicionalmente, arautos dos ajustes fiscais permanentes e da privatização, passam a afirmar que "[...] o retorno social de se ter um sistema de saúde mais adequado supera seu custo financeiro para qualquer país, independentemente de seu PIB" (Srour, 2020). Até mesmo o editorial, de 3 de abril de 2020, do Financial Times, uma espécie de catedral do liberalismo inglês, propugna que "[...] reformas radicais - invertendo a direção política predominante das últimas

AYLENE BOUSQUAT, MARCO AKERMAN, ÁQUILAS MENDES, MARÍLIA LOUVISON, PAULO FRAZÃO e PAULO CAPEL NARVAI são professores do Departamento de Política, Gestão e Saúde da Faculdade de Saúde Pública da USP. 
quatro décadas - precisarão ser colocadas sobre a mesa. Os governos terão que aceitar um papel mais ativo na economia. Eles devem ver os serviços públicos como investimentos, e não como passivos, e procurar maneiras de tornar os mercados de trabalho menos inseguros. A redistribuição estará novamente na agenda" ("Virus Lays...”, 2020). Decerto que essas frases podem não passar de meros depoimentos oportunistas e utilitaristas frente à perplexidade do mundo diante da pandemia, mas não cabe dúvida de que assinalam o fracasso de certas políticas de austeridade fiscal e de desmontagem de direitos que marcam políticas públicas desconectadas de necessidades sociais.

No caso brasileiro, o SUS foi objeto de constantes ataques nos últimos anos. Observa-se uma sucessão de políticas de desmantelamento associadas a um quadro de brutal desfinanciamento (Giovanella et al., 2019; Mendes \& Carnut, 2020a). É digno de nota que os debates sobre esses ataques passaram ao largo da opinião pública, sendo que os movimentos de defesa do SUS tinham dificuldades em romper a fronteira do chamado movimento sanitário e alcançar parcelas mais amplas da sociedade. Após o início da pandemia esse quadro começou a apresentar mudanças e o SUS passou a ser valorizado positivamente quase que diariamente, registrando-se depoimentos em sua defesa, vindos de bocas e lavras nas quais jamais estiveram presentes. Até mesmo o Jornal Nacional citou com destaque o artigo 196 da Constituição, que enuncia que a "saúde é um direito de todos e um dever do Estado". Independentemente das mudanças de posições de diversos atores, um dos poucos consensos nacionais é que sem o enorme esforço dos trabalhadores do SUS a impensável e triste marca de cerca de 250 mil óbitos notificados após um ano do primeiro caso diagnosticado com Sars-Cov-2 no Brasil seria ainda maior.

No entanto, é preciso reafirmar que a resposta brasileira, assim como a global, tem sido tímida e compreendida como "muito pouco", "muito tarde", na imensa maioria dos países ("Covid-19...”, 2020). As políticas mais efetivas de rastreamento e isolamento de casos e contatos associadas à diminuição drástica da circulação da população têm melhores respostas e os países que assim o fizeram têm pressionado muito menos seus serviços de saúde. Infelizmente, na maioria dos países, o foco não são as medidas coletivas e sim a tentativa de garantir apenas a atenção individual para os acometidos pelo Sars-Cov-2, buscando-se o contínuo aumento da capacidade hospitalar disponível, o que se mostra claramente insuficiente (Lowy Institute, 2021).

O enfrentamento e superação da pandemia não se resolve com abordagens individuais, são necessárias fortes ações coletivas, com planejamento amplo, incluindo planejamento e cooperação internacionais. Cada um só estará seguro quando todos os habitantes do planeta estiverem seguros. Essa constatação recoloca na ordem do dia valores como a solidariedade e a equidade, que andavam tão "esquecidos" na agenda neoliberal.

Solidariedade e equidade são a base da construção dos sistemas universais de saúde, como se dá com o nosso SUS. Exatamente por isso, ganha relevo, no atual cenário, apontar suas principais fragilidades e fortalezas no enfrentamento da pandemia de covid-19. 


\section{SISTEMAS DE SAÚDE \\ E NECESSIDADES NO MUNDO DA COVID-19}

Os sistemas universais de saúde, como os conhecemos hoje, são recentes na história e se consolidaram como tal em meados do século XX, fundamentalmente após a Segunda Guerra Mundial, tais como os do Reino Unido, da França, da Alemanha, do Canadá, da Suécia, posteriormente, da Espanha e, tardiamente, o SUS no Brasil (Giovanella et al., 2008). A função dos sistemas de saúde, genericamente, é solucionar os problemas de saúde dos indivíduos, comunidades e países e contribuir para a melhoria das condições de saúde. Os sistemas não são separados da sociedade. De um modo mais abstrato podem ser entendidos como a resposta social organizada às condições de saúde da população. No caso da pandemia de covid-19, evidentemente todos os sistemas estão submetidos a um imenso estresse, pois as sociedades cobram respostas em uma velocidade nunca demandada.

Cabe assinalar que o marco referencial para pensar qualquer política de saúde deveria ser o conceito de necessidades em saúde. Por ser carregada de valor, essa noção implica uma posição ético-política. Essa posição pode se orientar com base nos direitos humanos, em que as necessidades são aspirações ligadas ao direito social à saúde e à obrigação do Estado de assegurar o seu pleno exercício, ou pode estar subordinada à noção de responsabilização individual pela saúde, o que implica reduzir as necessidades àquilo que se manifesta como procura por serviços, e concentrar os esforços nas formas mais eficientes de alocação de recursos para responder a essa demanda (Campos \& Mishima, 2005). Nessa acepção o conceito de "saúde" é reduzido à ideia de "serviços de saúde". Embora seja nítida a distinção entre o significado dos termos, há um propósito claro de transformar a saúde, um bem imaterial, indivisível e inapropriável (Narvai \& Frazão, 2012), em algo que pode se materializar, por meio do consumo de um serviço sob as leis de mercado. O sentido último de qualquer sistema de saúde, especialmente os sistemas universais, deveria ser responder às necessidades de saúde da população, não apenas por meio de uma rede integrada de serviços estruturados dentro do setor, mas sobretudo por políticas públicas intersetoriais, subordinando os demais interesses (do mercado, dos provedores, da indústria etc.) a essas necessidades.

Assim, todos os sistemas enfrentam o desafio de equacionar as novas necessidades em saúde colocadas pela pandemia, a fim de produzir um arranjo equilibrado entre as necessidades coletivas e individuais. $\mathrm{O}$ que tem ficado claro nos últimos meses é que a melhor forma de equacionar essas novas necessidades passa por uma ação clara e inequívoca do Estado.

\section{SISTEMAS UNIVERSAIS DE SAÚDE OU PLANOS DE SAÚDE?}

Todos compreendem, de imediato, o adágio popular segundo o qual "está vendendo saúde" uma pessoa que aparentemente não está doente e que, além disso, demonstra estar desfrutando a vida em boas condições físicas e psicológicas. Mas há nessa expressão, consagrada pelo senso comum, algumas armadilhas, embutidas no verbo vender e no substantivo saúde. 
A armadilha do "vender saúde" reside no fato de que saúde não se vende e, portanto, não se compra. É possível a alguém comprar bens relacionados com a saúde, como medicamentos e equipamentos e até mesmo cuidados de saúde, que vão de consultas a cirurgias, passando por exames complementares e curativos variados. Mas a compra não assegura saúde. Por essa razão, ninguém vende saúde para ninguém.

A cilada de "comprar saúde", presente em situações como as de titulares de planos de saúde, consiste em que simplesmente não é possível comprar saúde, pois essa condição não resulta da mera aquisição e consumo de bens e serviços, mas de condições sociais de existência que vão muito além da sua importante dimensão biológica, como fica muito claro na pandemia. Costuma-se falar, a propósito, em "produção social da saúde", uma vez que as condições de saúde das populações resultam, em cada território e em cada população, de complexas interações entre as características biológicas de cada indivíduo na população e o modo como se articulam e interagem conjuntos específicos de variáveis que a literatura científica convencionou denominar de "determinantes sociais do processo saúde-doença-cuidado" (Narvai \& Frazão, 2012).

A chegada da pandemia de covid-19 ao Brasil e a sua propagação pelo vasto território deram relevo dramático a esses aspectos, tirando-os de algum modo do plano teórico e dando-lhes concretude no cotidiano da vida social. Para muitas pessoas foi surpreendente constatar que não lhes bastava ter um "plano de saúde", pouco importando se era dos mais modestos ou "VIP", como é costume se referir aos mais caros e que incluem um maior número de "benefícios e coberturas" (Narvai, 2011). Frente à condição social - de dimensão coletiva, portanto - de não se dispor de uma vacina durante vários meses, não haver possibilidade terapêutica medicamentosa e não se dispor de quantidade suficiente de leitos para terapia intensiva, independentemente de se tratar de hospitais públicos ou particulares, foi imperioso reconhecer que não há saídas individuais para o problema. Era simplesmente inútil ter em mãos um plano de saúde, pois não havia o que acessar. Nesse caso, mais decisivo do que ter poder aquisitivo para comprar, é crucial poder acessar. Mais: era indispensável, por se tratar de uma epidemia, que todos acessassem, pois o efeito de imunidade populacional é adquirido em processo sanitário complexo, que torna a soma $1+1$ muito maior do que 2 , seu resultado matemático.

A pandemia de covid-19 e o seu enfrentamento no Brasil e em outros países impuseram o reconhecimento de que a saúde é uma condição que, em populações e indivíduos, corresponde a muito mais do que não ter alguma doença, pois não se esgota em um corpo, quando estão envolvidos vírus, bactérias e outros microrganismos. Embora esse fato tenha um robusto fundamento em conhecimentos científicos, é bem difícil sua aceitação por parte de pessoas que não admitem restrições, senão as determinadas pela lei, do pleno exercício de sua autonomia e liberdade de ir, vir e agir, preservando ao máximo a expressão das individualidades. Tais pessoas simplesmente não se reconhecem como parte de um conjunto que é afetado pelo que ocorre com cada um que o integra, pois têm muitas dificuldades para compreender e, sobretudo, aceitar que nessas situações há um efeito 
de grupo, coletivo portanto, que transcende o que ocorre com cada membro do grupo, tomado individualmente.

Frente a uma epidemia com as características da pandemia da covid-19, emergiu com força gigantesca a necessidade de planejar e executar estratégias sanitárias que, pondo em primeiro plano a proteção coletiva, implicaram restrições, fundamentadas em conhecimentos científicos, à livre movimentação de indivíduos e à ação de agentes econômicos. Mas essa necessidade não foi admitida pelo governo federal brasileiro, que, durante todo o desenrolar do período pandêmico, adotou uma postura anticientífica e negacionista da gravidade sanitária.

Em nome da saúde pública, com base na ciência, e tendo em vista as características do sistema de saúde, era preciso renunciar a parte das liberdades de ir, vir e agir. Não foi, nunca é, fácil aceitar isto. A proteção sanitária de todos colidiu frontalmente com a ideologia liberal, segundo a qual nada nos indivíduos pode estar subordinado ao interesse público. Ainda que esse interesse se refira ao controle sanitário de uma pandemia.

Ademais, ao descortinar as desigualdades, a pandemia de covid-19 pressiona por respostas mais equânimes das políticas sociais e de saúde. O reconhecimento dos determinantes sociais indica a necessidade de redesenhar a prestação de serviços de saúde, com igualdade e justiça social. Em uma análise de competência estrutural dos sistemas de saúde é fundamental reconhecer que saúde e doença são do campo da política e que, sem fortalecer as redes sociais e apoiar as comunidades, não se produzirá equidade estrutural, necessária para reduzir desigualdades e vulnerabilidades (Metzl, Maybank \& Maio, 2020).

\section{O BRASIL CONTA COM O SUS, MAS 0 GOVERNO FEDERAL NÃO 0 QUER}

Desde sua criação, pela Constituição de 1988, o SUS vem desenvolvendo sua institucionalização em consonância com os princípios e diretrizes inscritos na Carta Magna. Nesses mais de 30 anos o sistema criou um modelo de governança no contexto federativo continental brasileiro capaz de compatibilizar a "participação da comunidade", por meio de conselhos e conferências de saúde, com a gestão descentralizada, instituindo comissões intergestoras que reúnem dirigentes do SUS dos níveis federal, estadual e municipal e financiamento tripartite que onera os orçamentos da União, estados e municípios, nos termos da lei, respeitando-se a autonomia que a Constituição assegura aos entes federativos. Consagrou-se, nessas instâncias de governança, um modus operandi que implica tomar decisões que dizem respeito ao sistema como um todo, com base no princípio do consenso, assentado em evidências científicas. O modelo de governança, republicano e democrático, vem inspirando o delineamento de outros sistemas nacionais, como os de segurança pública e de assistência social. Segundo esse modelo, os entes federativos dispõem de autonomia, exercendo as competências que a Constituição lhes atribui. Assim, cabe ao governo federal comandar o SUS em nível nacional, o que implica planejar, coordenar, executar e avaliar ações e operações que dizem respeito ao país. Tal é o caso do enfrentamento de epidemias e pandemias.

Porém, contrariando esse modelo de governança, cuja tessitura supõe respeito mútuo e práticas democráticas, o governo 
federal vem implementando uma estratégia própria, conflitante com as adotadas pela maioria dos demais entes federativos, que vem sendo considerada uma política deliberada de não enfrentar a pandemia (Brum, 2021). Inversamente ao que seria desejado, observa-se uma descoordenação nacional, que fratura o pacto federativo (Narvai, 2020). Em um regime de escassez de solidariedade, a autonomia dos entes federativos prevaleceu, muitas vezes em regime de competição, reforçando as desigualdades estruturais.

Por outro lado, como visto em outros momentos de crise no SUS, muita invenção foi realizada e a produção do cuidado em redes de atenção nos territórios foi potencializada e articulada com a vigilância e com os serviços de Atenção Básica. Cabe considerar ainda o fortalecimento do papel das instâncias estaduais no momento da pandemia, exercendo coordenação na organização da informação, vigilância e vacinação, bem como na distribuição da oferta de leitos de UTI por meio das centrais reguladoras estaduais de urgência e emergência.

Sem dúvida, uma das estratégias mais bem-avaliadas e com bons resultados do SUS foi a ampliação das equipes de Atenção Básica, com priorização da Estratégia Saúde da Família. Esse locus é essencial para o enfrentamento da pandemia especialmente por seus atributos de responsabilidade territorial, orientação comunitária e sua forte capilaridade em todo o território nacional, ou seja, todos os elementos para uma abordagem comunitária de vigilância da saúde estão presentes (Medina et al., 2020). Mais do que nunca, faz-se necessária a articulação do individual com o coletivo, a atuação integrada no âmbito das unidades de saúde com os territórios, a comunidade e seus equipamentos sociais. É importante que a reorganização do processo de trabalho na APS no contexto da epidemia se faça de modo a preservar os seus atributos de acesso, longitudinalidade, coordenação do cuidado, abordagem familiar e abordagem comunitária. A continuidade do cuidado às condições crônicas tem ocorrido especialmente nesses serviços, que precisam também manter os cuidados à gestação e à primeira infância e ainda dar respostas ao crescente aumento da demanda em saúde mental e usuários com sequelas da covid-19. Ademais, é necessário manter o apoio social aos grupos vulneráveis, ao mesmo tempo em que se garantem as condições de proteção dos trabalhadores e da população.

Por outro lado, a pandemia amplificou as importantes desigualdades no acesso, cobertura e utilização de serviços de média e alta complexidade presentes no país na atenção à saúde das condições crônicas, especialmente no acesso à atenção especializada e hospitalar no SUS (Tanaka et al., 2019). Na pandemia, a hegemonia do atendimento de urgência ficou evidenciada com a centralidade dos prontos atendimentos e a priorização da garantia de leitos. A consequente redução dos atendimentos eletivos inviabiliza as filas de espera para as especialidades, uma situação que pode se agravar cada vez mais e que será mais um grande desafio para o sistema de saúde brasileiro. O princípio da integralidade no SUS é constantemente desafiado no sentido da produção das linhas de cuidado em redes e, de alguma forma, o SUS tem acúmulos que possibilitaram a rápida organização de fluxos e protocolos de aten- 
dimento nos vários pontos de atenção da rede. $\mathrm{O}$ adoecimento dos trabalhadores e a sobrecarga exercida no sistema de saúde são uma realidade que só tem se agravado.

Outro ponto que precisa ser destacado no cenário das políticas de saúde são as importantes questões de promoção à saúde partindo do conceito ampliado de saúde: "como um conjunto de estratégias e formas de produzir saúde, no âmbito individual e coletivo" (Brasil, 2014). As ações intersetoriais, colocando na agenda a sustentabilidade, fortalecendo a participação social e o comprometimento da equidade, são estratégias centrais para o enfrentamento da pandemia. São também fundamentais o empoderamento e a participação social na implementação das medidas de saúde pública, o que pode ser feito através da disseminação de informação válida e adequada, culturalmente apropriada, abordando todos os aspectos de interface com a covid-19, não só em termos de proteção individual, mas principalmente no aumento da resistência coletiva. As experiências nas comunidades do Morro do Alemão (RJ) e de Paraisópolis (SP) são alguns dos inúmeros e exitosos exemplos de articulação entre as equipes do SUS e a população organizada.

Para além dos recursos de atenção à saúde de que o SUS dispõe para enfrentar a pandemia, é necessário também alocar recursos financeiros, suficientes e seguros. Mas essa não tem sido a prática de financiamento do SUS por parte do governo federal, ao longo de sua história. Não obstante, esse quadro está sendo ainda mais agravado no contexto da crise sanitária com a magnitude da covid-19. Quando se compara o enfrentamento dos países ao coronavírus, o Brasil revela-se como uma experiência muito particular, pois a chegada da pandemia encontrou o SUS combalido e sentindo os efeitos dos recorrentes embates por seu financiamento adequado. O sistema já dava sinais fortes de diminuição de sua sustentabilidade financeira, perdida ao longo de suas três décadas de existência, configurando o cenário de subfinanciamento, causado principalmente pela perda crescente de recursos federais. Duas evidências (Mendes \& Funcia, 2016) contribuem para caracterizar esse subfinanciamento: a) o gasto do Ministério da Saúde com ações e serviços públicos em saúde permaneceu no patamar de $1,7 \%$ do PIB entre 1995 e 2019, não sendo alterado nesse período; e b) se o artigo 55 das Disposições Constitucionais Transitórias da Constituição Federal fosse aplicado, 30\% dos recursos da Seguridade Social deveriam ser destinados à saúde, mas isso nunca foi feito. Em 2019, o Orçamento da Seguridade Social (OSS) foi de R \$ 750,1 bilhões, sendo que se destinados $30 \%$ à saúde, considerando os gastos do governo federal, esse valor corresponderia a cerca de R $\$ 225$ bilhões. Porém, a dotação do Ministério da Saúde foi de R\$ 122,3 bilhões em 2019, com uma diferença de R \$ 102,7 bilhões a menos, correspondendo a apenas $16,5 \%$ do OSS (Mendes \& Carnut, 2020a). Em três décadas o SUS perdeu o equivalente à metade dos recursos financeiros federais de que dispunha quando foi criado.

Além desse subfinanciamento crônico do SUS, o país passou a experimentar um processo de desfinanciamento do seu sistema universal de saúde desde a aprovação da Emenda Constitucional n $n^{\circ}$ 95/2016 (EC 95), que congelou o gasto público por 20 anos - uma severa medida de austeri- 
dade fiscal, sem precedentes no mundo. A partir dessa EC 95, o gasto do Ministério da Saúde foi congelado em $15 \%$ da receita corrente líquida do governo federal de 2017, a ser atualizado anualmente tão somente pela variação do índice inflacionário IPCA/IBGE, até 2036. Para se ter a dimensão da magnitude dessa medida, a perda de recursos desde 2018 até 2020 alcançou o patamar de $\mathrm{R} \$ 22,5$ bilhões (Mendes \& Carnut, 2020b).

Assim, se, antes mesmo da crise sanitária do coronavírus, o investimento em gasto público em saúde estivesse acontecendo sem as interdições realizadas em seu orçamento federal, o SUS poderia ter ampliada a sua capacidade instalada para o enfrentamento da pandemia. Contudo, quando a pandemia de covid-19 chegou oficialmente ao Brasil, com o primeiro caso confirmado em fevereiro de 2020, o SUS já estava debilitado pelos 32 anos de subfinanciamento que lhe vem sendo imposto pela ordem neoliberal. Esse quadro desalentador foi agravado ainda mais nos últimos três anos pelo franco desfinanciamento derivado da EC 95/2016.

Durante 2020, o primeiro ano da pandemia, o gasto para o seu enfrentamento foi baixo, correspondendo a apenas R $\$ 37,6$ bilhões (valores liquidados), sendo 30,4\% do total do orçamento do Ministério da Saúde para 2020, assim distribuídos: 22,2\% para Transferências para Estados/DF; 58,5\% para Transferências para os Municípios; $15,0 \%$ para aplicação direta pelo $\mathrm{MS}$; e $4,3 \%$ para Transferência ao Exterior (Conselho Nacional de Saúde, 2020a).

A proposta orçamentária do Ministério da Saúde para 2021, em plena continuidade e ascensão da pandemia, foi reduzida para o valor do piso federal calculado pela regra da EC 95, sendo suspensa apenas para 2020. $\mathrm{Na}$ prática, isso significa que, para 2021, o valor está mais de $\mathrm{R} \$ 40$ bilhões menor que o de 2020, não incluindo o último crédito extraordinário aberto, no valor de R\$ 20 bilhões, para as vacinas nos últimos dias do ano (Funcia, 2021). Nesse contexto, o Ministério da Saúde contará com bem menos recursos do que em 2020 e anos anteriores, para responder às necessidades de saúde da população, não restritas apenas ao enfrentamento da covid-19. Quando o Congresso Nacional aprovar o orçamento federal (o que não ocorrera até o final de fevereiro de 2021), ao Ministério da Saúde caberá R\$ 123,8 bilhões, montante inferior ao de 2020 ( $\mathrm{R}$ 125,2 bilhões). Nesse quadro de escassos recursos orçamentários, o Conselho Nacional de Saúde aprovou que o valor mínimo para a saúde para o orçamento de 2021 deveria ser de R\$ 168,7 bilhões, de acordo com a petição pública "O SUS merece mais em 2021" (Conselho Nacional de Saúde, 2020b).

Os recursos cronicamente insuficientes destinados ao SUS, diminuídos ainda mais para o enfrentamento dessa grave crise sanitária, no contexto de uma crise econômica global de longa depressão que atinge o mundo, incluindo o Brasil (Roberts, 2016), motivam indignação em praticamente toda a sociedade brasileira, com a óbvia exceção dos apoiadores incondicionais do governo federal e de sua política ultraliberal. É necessário que a saúde das brasileiras e brasileiros seja tratada com o devido respeito que seres humanos merecem, dignos de uma vida que deve ser valorizada e posta acima dos lucros crescentes de capitalistas, cuja concentração 
da riqueza global não para de aumentar, em escala planetária.

\section{DENTRE MUITOS, OS DESAFIOS MAIS URGENTES DO SUS}

São muitos os desafios postos ao SUS neste momento, e todos parecem urgentes. Vão da definição dos modelos assistenciais aos padrões de gestão, passando pelo aprimoramento dos sistemas de informação em saúde e a inexistência de uma carreira nacional, interfederativa, multiprofissional para os profissionais do sistema, dentre vários outros. Esses desafios são crônicos, mas foram agudizados pela pandemia de covid-19, que exigiu reinvenção e inovação quase instantâneas do SUS, especialmente na conexão, capilaridade e integração dos serviços e ações de saúde. Por outro lado, e não por acaso, no momento de ampliar a cobertura dos serviços de saúde para responder ao aumento da demanda imposta pela pandemia, alternativas privadas foram utilizadas em diversos estados, expressando propostas de empresariamento e inclusão de lógicas mercantis nos serviços de saúde. Em diversos desses casos foram comuns a indicação de superfaturamento e baixa qualidade dos serviços. A mercantilização por dentro e por fora do sistema de saúde, com indícios de ampliação dos processos de privatização ao longo da pandemia, precisa ser monitorada e denunciada, principalmente quando coloca em risco a vida das pessoas e a capacidade do Estado em responder às necessidades da população, como o ocorrido com alguns hospitais de campanha.

Reduzir desigualdades e vulnerabilidades e ampliar o conceito de saúde foram e con- tinuam sendo a aposta do sistema universal de saúde no Brasil. E, nesse sentido, o SUS precisa ser fortalecido e respeitado como patrimônio da sociedade brasileira. Uma resposta efetiva à pandemia só é possível com o SUS produzindo e distribuindo vacinas, monitorando a transmissão da doença e o uso dos serviços e, acima de tudo, cuidando das pessoas na medida de suas necessidades. É preciso um Estado, uma política pública, um sistema de saúde universal, que salve vidas de maneira igualitária, reconhecido como um importante recurso no enfrentamento da pandemia, onde "todas as vidas importam". O princípio da universalidade do SUS, que fez do nosso sistema de saúde um dos poucos triunfos neste momento, deve continuar resistindo, como vem fazendo bravamente desde sua criação.

Vale lembrar que os atributos desejáveis para a resiliência dos sistemas de saúde (Fridell et al., 2020) se relacionam a um financiamento adequado, boas redes de serviços de saúde, bom desempenho da força de trabalho, bons sistemas de informação, acesso equitativo a tecnologias em saúde, e, acima de tudo, com fortes sistemas de liderança, coordenação, governança e regulação. O enfrentamento da pandemia no Brasil tem explicitado importante fragilidade na coordenação e no processo regulatório, principalmente do governo federal, no sentido da defesa do interesse da sociedade, tanto na regulação do sistema de saúde, considerando a regulamentação legal necessária ao enfrentamento da pandemia, como na regulação assistencial, com a garantia do acesso ao cuidado necessário. Este inclui distanciamento, máscaras, álcool em gel, monitoramento, testes diagnósticos, exames, consultas de acompanhamento, leitos 
e leitos de UTI quando necessário e, com a garantia de trabalhadores da saúde capacitados e protegidos, medicamentos e oxigênio para que funcionem adequadamente. O planejamento e a gestão dos sistemas e serviços de saúde precisam estar alinhados a essas necessidades e se responsabilizar pela sua pronta resposta.

Não obstante tantas carências e urgências, é preciso reconhecer o caráter de emergência de dotar o SUS de mais recursos e da estabilidade do seu financiamento. Além disso, é necessário definir, em processo democrático que envolva amplos setores da sociedade brasileira, um plano estratégico para recuperar as perdas que foram impostas ao sistema nas últimas décadas, com o objetivo de colocar o nível de alocação pelo menos no patamar equivalente ao que o SUS tinha quando foi criado em 1988. Mas é igualmente urgente assegurar a manutenção das vinculações orçamentárias em todos os entes federativos, pois o SUS não pode, para cumprir sua missão constitucional, contar apenas com a dedicação dos profissionais que lhe dão vida no cotidiano das unidades e serviços públicos de saúde, à custa de baixíssimos salários e de ambientes laborais degradados e sem equipamentos e instalações adequados. Para enfrentar a pandemia em 2021 e as consequências dela decorrentes para os próximos anos, é indispensável que o governo federal recupere financeiramente, o mais breve possível, o nosso sistema universal de saúde, cessando as restrições impostas à sua capacidade de cumprir plenamente seus princípios e diretrizes constitucionais e que estão levando ao seu desfinanciamento. Além disso, em parceria com instituições científicas e respeitando estados e municípios como entes federativos autônomos, deve redefinir democraticamente a estratégia nacional para enfrentamento da pandemia, pois a crise sanitária que ela provoca não pode ser combatida sem o fortalecimento do SUS, que, mesmo com recursos insuficientes, vem obtendo resultados muito significativos, salvando a vida de milhares de brasileiros. Nosso sistema universal de saúde, nosso SUS é, por essa razão, agora mais necessário do que nunca. 


\section{REFERÊNCIAS}

BRASIL. Ministério da Saúde. Portaria MS n 2.446/2014, de 11/11/2014. Redefine a Política Nacional de Promoção da Saúde (PNPS). DOU, 13/11/2014. Seção 1, pp. 68-70.

BRUM, E. "Pesquisa revela que Bolsonaro executou uma 'estratégia institucional de propagação do coronavírus'". El País Brasil, janeiro/2021. Disponível em: https:// brasil.elpais.com/brasil/2021-01-21/pesquisa-revela-que-bolsonaro-executou-umaestrategia-institucional-de-propagacao-do-virus.html.

CAMPOS, C. M. S.; MISHIMA, S. M. (2005). "Necessidades de saúde pela voz da sociedade civil e do Estado". Cadernos de Saúde Pública, 21(4). Disponível em: https://doi. org/10.1590/s0102-311×2005000400029.

CNS - Conselho Nacional de Saúde. Boletim Cofin, vol. 21, 2020a Disponível em: http://conselho.saude.gov.br/images/comissoes/cofin/boletim/Boletim_2020_1221_ Tab1-4_Graf1_ate_20_RB-FF-CO_OK-DIVULGAR_x.pdf.

CNS - Conselho Nacional de Saúde. Petição Pública: "O SUS merece mais em 2021! CNS reivindica manutenção de piso emergencial no valor de R\$ 168,7 bilhões". Site do CNS, 6/8/2020b. Disponível em: http://conselho.saude.gov.br/ultimas-noticias-cns/1297peticao-publica-voce-vai-deixar-o-sus-perder-mais-r-35-bilhoes-em-2021.

"COVID-19: too little, too late?". The Lancet, vol. 395, 2020.

FRIDELL, M. et al. "Health system resilience: what are we talking about? A scoping review mapping characteristics and keywords". International Journal of Health Policy and Management, 9 (1).

FUNCIA, F. R. "Tragédia de saúde de Manaus: mais uma consequência do desfinanciamento do SUS e pelo descaso com o direito à vida pelo governo brasileiro". Domingueira, janeiro/2021. Disponível em: http://idisa.org.br/domingueira/ domingueira-n-01-janeiro-2021\#a0.

GIOVANELLA, L. et al. "Médicos pelo Brasil: caminho para a privatização da atenção primária à saúde no Sistema Único de Saúde?". Cadernos de Saúde Pública, 35(10), 2019.

GIOVANELLA, L. et al. Políticas e sistema de saúde no Brasil. 1 1a ed. Rio de Janeiro, Fiocruz/ Cebes, 2008.

LOWY INSTITUTE. "Covid Performance Index. Deconstructing Pandemic Responses website, 2021". Disponível em: https://interactives.lowyinstitute.org/features/covidperformance.

MEDINA, M. G. et al. "Atenção primária à saúde em tempos de covid-19: o que fazer?". Cadernos de Saúde Publica, 36(8), 2020.

MENDES, A.; CARNUT, L. "Capital, Estado, crise e a saúde pública brasileira: golpe e desfinanciamento". SER Social, 22, pp. 9-32, 2020a.

MENDES, A.; CARNUT, L. "Crise do capital, Estado e neofascismo: Bolsonaro, saúde pública e atenção primária". Revista da Sociedade Brasileira de Economia Política, 57, pp. 174-210, 2020b.

MENDES, A.; Funcia, F. R. "O SUS e seu financiamento", in Sistema de saúde no Brasil: organização e financiamento. Brasília, Abres/MS/Opas, 2016, pp. 139-68.

METZL, J. M.; MAYBANK, A.; MAIO, F. "Responding to the covid-19 pandemic: the need for a structurally competent health care system". Jama - Journal of the American Medical Association, vol. 324, 2020, pp. 231-2. 
NARVAI, P. C. "Grevistas do Maracanã e dupla porta do SUS". Idisa - Instituto de Direito Sanitário Aplicado, website, 2011. Disponível em: http://idisa.org.br/img/File/NarvaiPCGrevistasMaracanaDuplaPortaSUS.pdf.

NARVAI, P. C. "Terraplanismo epidemiológico". A Terra É Redonda, 16/3/2020. Disponível em: https://aterraeredonda.com.br/terraplanismo-epidemiologico/.

NARVAI, P. C.; Frazão, P. "Práticas de saúde pública” in A. A. Rocha; C. L. G. Cesar; H. Ribeiro (orgs.). Saúde pública: bases conceituais. 2a ed. São Paulo, Atheneu, 2012, pp. 307-35.

ROBERTS, M. The long depression: how it happened, why it happened, and what happens next. Chicago, Haymarket Books, 2016.

SANTOS, B. S. A cruel pedagogia do vírus. Coimbra, Almedina, 2020.

SROUR, S. "Prudência com as políticas públicas". Folha de S. Paulo, 15/7/2020. Disponível em: https://www1.folha.uol.com.br/colunas/solange-srour/2020/07/prudencia-comas-politicas-publicas.shtml?utm_source=newsletter\&utm_medium=email\&utm_ campaign=newscolunista.

TANAKA, O. Y. et al. "Hipertensão arterial como condição traçadora para avaliação do acesso na atenção à saúde". Ciência \& Saúde Coletiva, 24(3), 2019.

"VIRUS LAYS bare the frailty of the social contract". Financial Times, 2020. Disponível em: https://www.ft.com/content/7eff769a-74dd-11ea-95fe-fcd274e920ca. 